\title{
Study on enhanced bioremediation effect of oil-bearing dredging sediment
}

\author{
Lei Chao ${ }^{1}$, Xiaoyun $\mathrm{Mo}^{2 *}$, Jia Meng ${ }^{3}$ and Yafeng $\mathrm{Li}^{4}$ \\ ${ }^{124}$ School of municipal and environmental engineering, Shenyang Jianzhu University, Shenyang, Liaoning Province, 110168, China \\ ${ }^{3}$ Liaoning Branch of China Railway Inter-City Planning and Construction Co., Ltd, Shenyang, Liaoning Province, 110000, China
}

\begin{abstract}
To solve the problem of difficult treatment of oil-bearing dredging sediment, the effects of three methods of microbial remediation, phytoremediation and combined bioremediation on the treatment of oily river dredging sediments were compared and studied, and the influence factors of microbial remediation were explored through static bacteria-fling tests. The results showed that the combined remediation method was better than the single biological method in treating bottom mud. The oil content of the treated sediment was $1.21 \mathrm{~g} / \mathrm{kg}$, and the removal rate was $95.31 \%$; the organic matter of the treated sediment was $72.30 \mathrm{~g} / \mathrm{kg}$, and the degradation rate was 37.33 . \%, which can meet the requirements in the "Control Standards of Pollutants in Sludge for Agricultural Use (GB4284-2018)" and can be used for agricultural purposes.
\end{abstract}

\section{Introduction}

Oil pollution in river sediment has been becoming more and more serious, and it is difficult to treat dredging sediment. Finding a suitable treatment technology is the research direction of many scholars. At present, the river dredging methods commonly used at home and abroad can be divided into three categories according to the principle, which are physical remediation (water transfer, dredging, etc.), chemical remediation (redox technology, passivation technology, etc.) and biological remediation (microbial remediation and phytoremediation) ${ }^{[1]}$. Compared with traditional physical methods and chemical methods, bioremediation has great economic advantages ${ }^{[2]}$. In addition, bioremediation emphasizes the restoration and reconstruction of the aquatic ecosystem and pays attention to the concept of balance and stability of the ecosystem, so it has been paid more and more attention ${ }^{[3]}$.

Bioremediation technology includes phytoremediation and microbial remediation. Using the microbial remediation method alone to treat the oily dredging sediment can reach agricultural standards, but it can not produce actual economic benefits, which is of little significance to the actual project. Therefore, it is considered that based on the research of phytoremediation and microbial remediation, the two treatment methods are combined to produce a synergistic effect. So that in the process of sediment remediation, the removal of sediment oil quality is better. when is applied in actual engineering, it can also produce certain economic and environmental benefits.
In this study, the sediment of the Qingshui River in Panjin City, Liaoning Province, polluted by petroleum pollutants from petrochemical companies was used as the tested sediment. The static bacteria-fling test was first used to determine the best reaction conditions for the microbial remediation method. On this basis, a combination of phyto-microbial remediation methods was carried out. Through the plant, microorganism, and combined bioremediation test of dredging sediment, the appropriate treatment process was determined, in order to provide an example for the treatment and disposal of oilbearing dredging sediment.

\section{Materials and Methods}

\subsection{Instruments and materials}

The tested sediment was taken from the Qingshui River in Panjin City, Liaoning Province, and its physical and chemical properties are shown in Table 1. Experimental reagents: potassium dichromate, nitric acid, concentrated sulfuric acid, hydrochloric acid, sodium hydroxide, ferrous ammonium sulfate, o-phenanthroline, ammonium molybdate, potassium hydrogen sulfate, potassium persulfate, potassium sodium tartrate, and ascorbic acid are all analytically pure. Distilled water is homemade.

Experimental instruments: UV-visible spectrophotometer, electric heating constant temperature blast drying oven, electronic analytical balance, magnetic stirrer, acidity meter, DC stabilized power supply, air compressor, rotameter, and aeration pump.

\footnotetext{
e-mail: leichao@sjzu.edu.cn

${ }^{2 *}$ Corresponding author's e-mail: moxiaoyun@stu.sjzu.edu.cn
} 
Table1.Test results of physical and chemical properties of oil-bearing sediment.

\begin{tabular}{cc}
\hline physicochemical indexes & Index values \\
\hline Oil content $(\mathrm{g} / \mathrm{kg})$ & 25.79 \\
Organic matter $(\mathrm{g} / \mathrm{kg})$ & 115.366 \\
Moisture content $(\%)$ & 83.50 \\
$\mathrm{pH}$ & 6.8 \\
\hline
\end{tabular}

\subsection{Experiment methods}

\subsubsection{Composition analysis of oil-bearing dredging sediment}

The oil content was measured by the gravimetric method. For oily bottom sludge contaminated by light petroleum products, the gravimetric extraction rate can reach more than $90 \%$.

Organic matter was measured by the potassium bichromate titrimetric method (oil-melt method). Even if the river sediment is polluted by petroleum products, the main component of the sludge is still organic matter.

\subsubsection{The static bacteria-fling test}

In the static test device, a bacterial agent was added. The bacterial agent is a high-efficiency petroleum-degrading bacterial agent developed by the research team's laboratory for the research on the project of repairing the pollution of ground crude oil. It belongs to Bacillus and is a denitrifying bacteria preparation. The bacterial agent reacted with the pollutants in the bottom mud, The effect of the ambient temperature, the concentration of bacterial agent and the aeration amount on petroleum hydrocarbon degradation rate was studied by the method of single factor experiment. On the basis of the single-factor test, the orthogonal method was used to optimize the repair conditions of oily bottom mud, and to determine the best reaction condition for microbial remediation test.

\subsubsection{The remediation test of oil-bearing dredging sediment}

4 parallel experiments were designed, the same quality of air-dried bottom mud was weighed in the each group of experiments and placed in the same polyethylene material paper cones. The $1 \#$ test was a controlled trial without adding any substance to the bottom mud. The test schemes are shown in Table 2.

Table 2. Schemes of the repair test.

\begin{tabular}{cc}
\hline Numbering & Schemes \\
\hline $1^{\#}$ & The tested sediment \\
$2^{\#}$ & The tested sediment+Ryegrass seeds \\
$3^{\#}$ & The tested sediment + Petroleum-degrading bacterial agents \\
& The tested sediment + Petroleum-degrading bacterial agents \\
& +Ryegrass seeds \\
\hline
\end{tabular}

The purpose of the $2^{\#}$ experiment was to investigate the repair effects of lawn plants on the tested dredging sediment. Ryegrass was the lawn plant that grew better in the previous growth test. The purpose of the $3^{\#}$ experiment was to investigate the repair effects of microorganisms on the tested dredging sediment. The purpose of the 4\# experiment was to investigate the repair effects of the combined application of plants and microorganisms on the tested dredging sediment. In the experiments, samples were taken regularly to detect oil content and organic matter in sediment and the detection was stopped when the relevant indicators of the bottom mud reached the land agricultural standards.

\section{Results \& Discussion}

\subsection{The optimization of microbial remediation conditions}

\subsubsection{Effect of ambient temperature}

The experiment was carried out at four temperatures: $15^{\circ} \mathrm{C}$, $20{ }^{\circ} \mathrm{C}, 25{ }^{\circ} \mathrm{C}$ and $30{ }^{\circ} \mathrm{C}$. The curve of the relationship between the petroleum hydrocarbon degradation rate and ambient temperature was obtained. As be shown in figure 1,the degradation rate of petroleum hydrocarbons continues to increase with the increasing temperature and reaches the peak value $(78.8 \%)$ when the temperature is $30^{\circ} \mathrm{C}$. When the temperature is low, the viscosity of the oily sediment increases, and the volatility of PAHs which are 
toxic to microorganisms decreases. So the function of microorganisms is weakened ${ }^{[4]}$. At the same time, low temperature will inhibit the activity of enzymes in microorganisms and weaken microbial metabolism ${ }^{[5]}$.

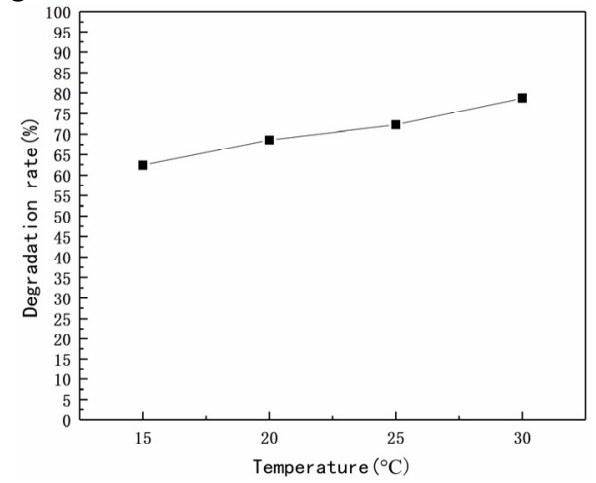

Figure 1.The effect of environmental temperature on the degradation rate of petroleum hydrocarbons.

\subsubsection{Effect of concentration of bacterial agent}

Under the condition that other factors remained unchanged, four bacterial concentrations and a blank sample were set up, namely $0 \mathrm{mg} / \mathrm{L}, 2.5 \mathrm{mg} / \mathrm{L}, 5 \mathrm{mg} / \mathrm{L}$, $7.5 \mathrm{mg} / \mathrm{L}$ and $10 \mathrm{mg} / \mathrm{L}$. The curve of the relationship between the degradation rate of petroleum hydrocarbons and the concentration of bacteria agent was obtained. As be shown in figure 2, when microbial agents are not added, the degradation rate of petroleum hydrocarbons is very low, only $8.2 \%$. In the experimental groups, the degradation rate of petroleum hydrocarbons increases at first and then decreases with the increasing bacterial concentration. When the bacterial concentration is $5 \mathrm{mg} / \mathrm{L}$, the degradation rate is $80.09 \%$. At this time, the degradation rate of petroleum hydrocarbons is the highest. If the concentration of bacteria is low, the concentration of petroleum hydrocarbons is higher than the number of bacteria. Thus the growth of microorganisms in the culture environment is inhibited and the treatment effect is not good. However, when the concentration of bacteria exceeds a certain concentration, microorganisms grow excessively, consuming a lot of nutrients and dissolved oxygen, and the growth of bacteria is affected ${ }^{[6]}$.

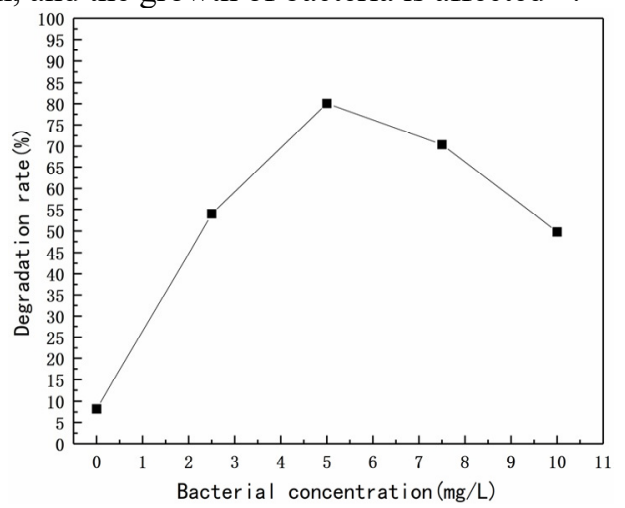

Figure 2. The effect of bacterial concentration on the degradation rate of petroleum hydrocarbons.

\subsubsection{Effect of aeration amount}

Under the condition that other factors remained unchanged, four groups of different aeration intensity and one blank sample were set up in the experiment, which were $0 \mathrm{~L} / \mathrm{h}, 10 \mathrm{~L} / \mathrm{h}, 20 \mathrm{~L} / \mathrm{h}, 30 \mathrm{~L} / \mathrm{h}$ and $40 \mathrm{~L} / \mathrm{h}$ respectively. The curve of the relationship between the degradation rate of petroleum hydrocarbons and the aeration amount was obtained. As be shown in Figure 3 when the aeration equipment is not used, the petroleum degradation rate is relatively low, only $50.1 \%$. In the test group, the degradation rate of petroleum hydrocarbons increases first and then slowly decreases with the increasing aeration amount. When the aeration amount is $20 \mathrm{~L} / \mathrm{h}$, the degradation rate is $76.6 \%$. At this time, the degradation rate of petroleum hydrocarbons is the highest. Although the microbial degradation of petroleum hydrocarbons can occur under both anaerobic and aerobic conditions, the degradation rate of petroleum hydrocarbons under aerobic conditions is much higher, far exceeding the degradation rate under anaerobic conditions ${ }^{[7]}$. The degradation process of petroleum substances is essentially their oxidation process. When the oxygen is insufficient, the growth and reproduction of microorganisms are inhibited, and the degradation rate becomes lower; when the oxygen concentration increases within a certain range, it will promote the metabolism of microorganisms and increase the degradation rate ${ }^{[8]}$.

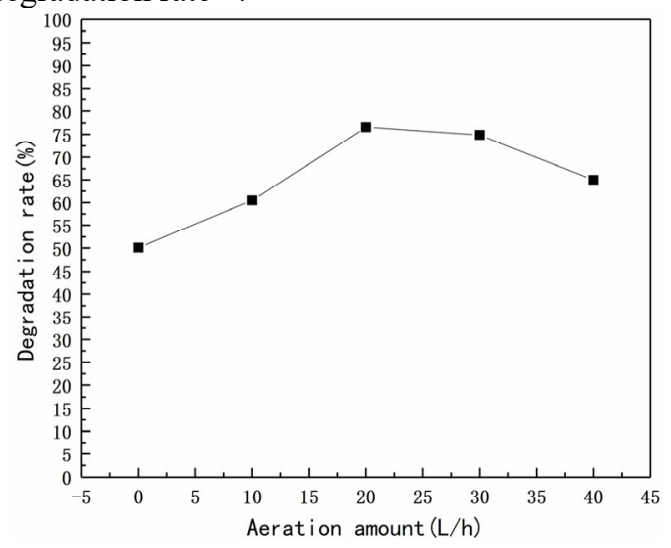

Figure 3. The effect of aeration amount on the degradation rate of petroleum hydrocarbons.

\subsubsection{Orthogonal test}

The above tests were performed under the condition that each test factor did not interfere with each other. But in the actual reaction, each influencing factor will have a certain mutual influence between each other, thereby affecting the treatment effect of the sediment. Therefore, the orthogonal test was used to determine the best process conditions for the microbial remediation to treat oily bottom mud. The factor levels of orthogonal test $\mathrm{L}_{9}\left(3^{3}\right)$ are shown in Table 3 , and the final degradation rate is used as the test index for analysis. The test results are shown in Table 4. 
Table 3. Factors and levels for orthogonal test

\begin{tabular}{cccc}
\hline Level/Variable & Temperature $\left({ }^{\circ} \mathrm{C}\right)$ & Dosage $(\mathrm{mg} / \mathrm{L})$ & Aeration $(\mathrm{L} / \mathrm{h})$ \\
\hline 1 & 20 & 4 & 15 \\
2 & 25 & 5 & 20 \\
3 & 30 & 6 & 25 \\
\hline
\end{tabular}

Table 4.Analysis of L9(3)3 test results

\begin{tabular}{ccccc}
\hline No. & Temperature $\left({ }^{\circ} \mathrm{C}\right)$ & Dosage $(\mathrm{mg} / \mathrm{L})$ & Aeration $(\mathrm{L} / \mathrm{h})$ & Degradation rate $(\%)$ \\
\hline 1 & 20 & 4 & 15 & 65.95 \\
2 & 20 & 5 & 20 & 69.26 \\
3 & 20 & 6 & 25 & 77.65 \\
4 & 25 & 4 & 20 & 75.40 \\
5 & 25 & 5 & 25 & 80.21 \\
6 & 25 & 6 & 15 & 88.30 \\
7 & 30 & 4 & 25 & 70.55 \\
8 & 30 & 5 & 15 & 74.72 \\
9 & 30 & 6 & 20 & 89.92 \\
$\mathrm{k}_{1}$ & 70.95 & 70.63 & 76.32 & \\
$\mathrm{k}_{2}$ & 81.30 & 74.73 & 78.19 & \\
$\mathrm{k}_{3}$ & 78.40 & 85.29 & 76.13 & \\
$\mathrm{R}$ & 10.35 & 14.66 & 2.06 & \\
\hline
\end{tabular}

Note: $\mathrm{ki}$ represents the average value of the i level of each factor, and $\mathrm{R}$ is the difference between the maximum average value and the minimum average value.

It can be seen from Table 4 that No. 9 has the best effect, with a removal rate of $89.92 \%$. It can be seen from the range analysis that the greatest influence on the degradation rate of petroleum hydrocarbons is the concentration of bacteria, and the least influence is the amount of aeration. Comparing the average removal rate of each factor at each level, it is concluded that the best reaction conditions for removing petroleum hydrocarbons from the bottom mud are: temperature of $30^{\circ} \mathrm{C}$, bacterial dosage of $6 \mathrm{mg} / \mathrm{L}$, and aeration amount of $20 \mathrm{~L} / \mathrm{h}$.

\subsection{Analysis of repair test results}

The changes in the oil content and organic matter of the oil-bearing dredging sediment in different remediation tests are shown in Figure 4, Figure 5, and Figure 6. The final degradation rate of the four groups of experiments is shown in Figure 7.The oil content and organic matter in all tests show a downward trend as a whole. The final petroleum hydrocarbon degradation rate and organic matter removal rate of the control test $1 \#$ are $20.98 \%$ and $10.27 \%$, respectively, indicating that the indigenous microorganisms in the sediment have a certain degrading effect on pollutants. The final degradation rate of test $2 \#$ is 4 times higher than that of the control group, which shows that the phytoremediation method has a obvious effect on the remediation of oily river sediment. The interaction between root exudates and microorganisms is the main reason for the decrease of oil content and organic matter in phytoremediation. It can be seen from Figure 5 that the oil content in the bottom mud decreases rapidly. The added high-efficiency petroleum-degrading bacterial agent can quickly degrade petroleum hydrocarbons through aerobic respiration. After the 35th day of the test, the degradation rate slows down. When the test reaches the 45th day, the oil content in the bottom mud is $2.81 \mathrm{~g} / \mathrm{kg}$, and the degradation rate is $89.1 \%$. However, at the beginning of the test, the removal rate of organic matter is slow. This may be due to the fact that the growth rate of microorganisms in the initial stage is less than the degradation rate of the bottom mud and the organic matter content decreases slowly. It can be seen from Figure 6 that the oil content of the bottom mud treated by the combined remediation method is $1.21 \mathrm{~g} / \mathrm{kg}$, the organic matter is $72.30 \mathrm{~g} / \mathrm{kg}$. The treated bottom mud index can meet the requirements in the "Control Standards of Pollutants in Sludge for Agricultural Use (GB4284-2018)". It can be seen from Figure 7 that the combined remediation method has a better treatment effect on the bottom mud than the single biological method. The final petroleum hydrocarbon degradation rate is $78 \%$ higher than the natural remediation, and the treatment time is not long, about 65 days. The combined remediation method degrades petroleum hydrocarbons in the bottom mud and at the same time by using the conditions of high nutrients 
in the bottom mud, we can obtain a batch of lawn plants,

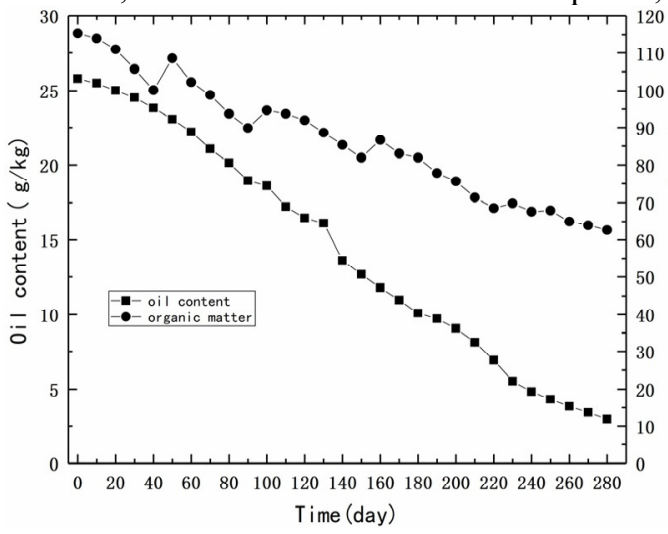

Figure 4. Change of oil content and organic matter of phytoremediation.

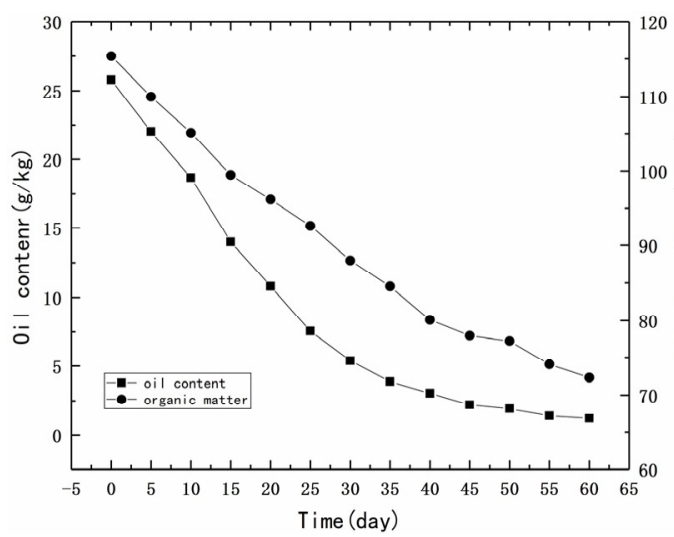

Figure 6. Change of oil content and organic matter of combined bioremediation.

\section{Conclusions}

(1) The optimal process conditions for the microbial remediation were determined by orthogonal test: temperature of $30^{\circ} \mathrm{C}$, bacterial dosage of $6 \mathrm{mg} / \mathrm{L}$, and aeration amount of $20 \mathrm{~L} / \mathrm{h}$.

(2) After remediation of oil-bearing dredging sediment through three methods: phytoremediation, microbial remediation and combined remediation, they all can meet the requirements of the "Control Standards of Pollutants in Sludge for Agricultural Use (GB4284-2018)" for agricultural purposes. Among them, the plant-microbe combined remediation method has the best effect. The final petroleum hydrocarbon degradation rate is $95.31 \%$, which is 4.54 times that of natural remediation (20.98\%) and is greater than phytoremediation and microbial remediation. In addition, the time of combined bioremediation is relatively short, only 65 days.

\section{Acknowledgments}

This research was funded by the China National Critical Project for Science and Technology on Water Pollution Prevention and Control (2018ZX07601-002), to which the

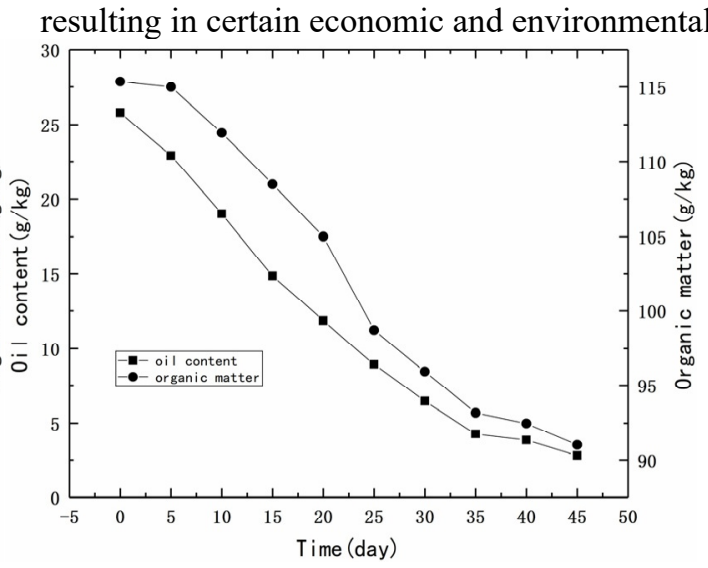

Figure 5. Change of oil content and organic matter of microbial agent.

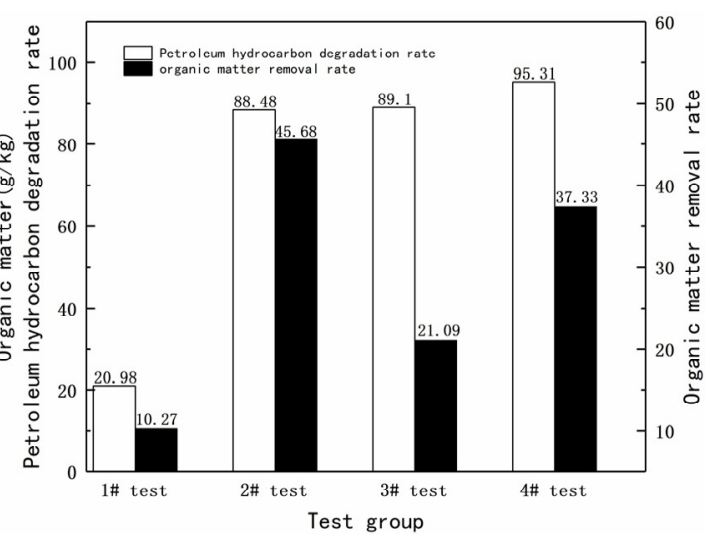

Figure 7.Petroleum hydrocarbon degradation rate and organic matter removal rate in different repair trials.

authors express their thanks.

\section{References}

1. Tayor,K.G.,Owens,P.N.(2009)Sediments in urban river basins: a review of sediment-contaminant dynamics in an environmental system conditioned by human activities. Journal of Soils and Sediments, 9: 281-303.

2. Perelo,L.W.(2010)Review:In situ and bioremediation of organic pollutants in aquatic sediments.Journal of Hazardous Materials, 177(1-3):81-89.

3. Liu,C.(2012)Experimental research on the remediation of sediment in black-odorous rural river by using biostimulant and microbial agent.Guangxi University.

4. Wei,R.R.(2013)Screening of high efficiency degradation bacterium about shanbei oil sludge and its degradation abilities.Xi'an University of Architecture and Technology.

5. Hao,H.Q.,Sun,Y.M.,et al.(2008)Research progress on microbial degradation of Petroleum hydrocarbons.Hebei Chemical Industry,31(12):4-6.

6. Zhang,X.J.(2018)The characteristics of pollutants in sediment and the research of in-situ controlling in 
Beiyun River,China.Dalian Ocean University.

7. Lu,G.H.,Wan,L.,et al.(2003)Research progress on bioremediation of soil contaminated by petroleum hydrocarbons.Ecology and Environment,12(2):220223.

8. Guo,Q.Y.(2016)The research of screening and degradating optimization of oil reduction bacteria in oil wastewater.Xi'an Polytechnic University. 